\title{
Uso de antimicrobianos pela população da cidade de Jataí (GO), Brasil
}

\author{
The use of antimicrobial drugs by the population \\ in the city of Jataí, State of Goias, Brazil
}

Alexandre Braoios ${ }^{1}$
Ana Cláudia Souza Pereira ${ }^{1}$
Adaís Alves Bizerra $^{1}$
Olmeny Ferreira Policarpo $^{1}$
Nayana Carvalho Soares $^{1}$
Adriano de Souza Barbosa $^{1}$

${ }^{1}$ Departamento de Biomedicina, Centro de Ciências Agrárias e Biológicas, Universidade Federal de Goiás - Unidade Jataí. BR 364 Km 192/3800 Cx Postal 03, Setor Industrial. 75.801-615 Jatai,GO.ab31@uol.com.br

\begin{abstract}
One factor that contributes to the emergence of multidrug-resistant microorganisms is the inappropriate use of antimicrobials. In this study 192 homes were visited to apply a questionnaire regarding the consumption habits of antimicrobials of all residents. The data revealed that $6.8 \%$ of participants had used antimicrobial agents in recent months. Users were predominantly female, aged between 20 and 59, with an income of 1 to 3 minimum salaries. Of the total, 9.1\% made use of antimicrobials without prescription and $4.6 \%$ did not complete the treatment cycle, citing either improvement in symptoms or side effects. The most reported reason for treatment was oropharyngeal infection. Inappropriate use of antibiotics was also detected, such as for the treatment of fever, influenza and allergy. Among the respondents, 20.5\% traditionally recommend the use of antimicrobials to family and friends. This study was conducted before the prohibition of the sale of antibiotics without a prescription. The majority of respondents are unaware of the risks of inappropriate use and a considerable percentage of individuals recommend these drugs to others. With the implementation of the law prohibiting sale without prescription, it is hoped that this problem will be minimized.
\end{abstract}

Key words Self-medication, Antimicrobials, Resistance to antibiotics
Resumo Um dos fatores que contribui para a emergência de microrganismos multirresistentes é a utilização inadequada de antimicrobianos. Neste estudo foram visitados 192 domicílios para aplicação de um questionário a respeito dos hábitos de consumo de antimicrobianos de todos os moradores. Os dados revelaram que 6,8\% dos participantes utilizaram antimicrobianos nos últimos meses. Os usuários eram predominantemente do sexo feminino, idade entre 20 e 59 anos e renda de 1 a 3 salário mínimos. Do total, 9,1\% fizeram uso de antimicrobianos sem prescrição e 4,6\% não concluíram o tratamento, alegando melhora dos sintomas ou devido aos efeitos colaterais. O motivo mais relatado para o tratamento foi infecção de orofaringe. Foi constatado também o uso de antimicrobianos de forma desnecessária, como para o tratamento de febre, gripe e alergia. Entre os entrevistados, 20,5\% possuem o hábito de indicar antimicrobianos para familiares e amigos. Este trabalho foi conduzido antes da proibição legal da venda de antimicrobianos sem receita médica. Grande parte dos entrevistados desconhece os riscos da utilização inadequada e foi observado um percentual considerável de indivíduos que indicam estas drogas a outros. Com a implantação da lei que proíbe a venda sem prescrição é esperado que este problema seja minimizado.

Palavras-chave Automedicação, Antimicrobianos, Resistência a antibióticos 


\section{Introdução}

Uma cepa microbiana é considerada resistente a um agente antimicrobiano quando é capaz de se multiplicar na presença de concentrações de drogas antimicrobianas mais altas do que as doses terapêuticas dadas a humanos e/ou animais. A resistência microbiana é um fenômeno biológico e natural que se tornou efetivamente evidente após a introdução da terapia antimicrobiana na década de 1940. Segundo Wannmacher ${ }^{1}$, o uso abusivo de antimicrobianos tem sido o grande responsável pela emergência de cepas resistentes. Assim, as taxas de resistência estão diretamente relacionadas às características de consumo de antimicrobianos por uma comunidade ou região. Dentre os fenômenos que estão definitivamente vinculados à emergência de resistência está o uso abusivo, indiscriminado e/ou inadequado de drogas antimicrobianas. Este grupo de drogas medicamentosas representa hoje um terço das prescrições médicas.

Dados da Organização Mundial de Saúde $(\mathrm{OMS})^{2}$ revelam que $50 \%$ das prescrições de antibióticos são inapropriadas. Outro estudo informa que dois terços do total de antibióticos são consumidos sem prescrição médica ${ }^{3}$. Outros estudos demonstram que dois terços das prescrições de antimicrobianos em pediatria restringem-se a cinco afecções do trato respiratório: otites, sinusites, faringoamigdalites, bronquites e pneumonias. ${ }^{4}$. Apesar de inúmeros trabalhos na literatura internacional terem demonstrado o pouco ou nenhum benefício do uso de antimicrobianos para muitas dessas morbidades, esta continua sendo uma prática comum nas diversas modalidades de atendimento ambulatorial ${ }^{4}$.

O uso abusivo de antibióticos para o tratamento de Infecções do Trato Respiratório (ITR) de etiologia viral é bastante comum, tanto em países desenvolvidos como naqueles em desenvolvimento. Diversos fatores contribuem para esse quadro: dificuldade para diferenciar clinicamente infecções virais das bacterianas; a crença inverídica de que o uso profilático de antibióticos poderia evitar complicações; a falta de controle na venda desses fármacos; o desconhecimento sobre os possíveis efeitos adversos associados ao uso inadequado de antibióticos, incluindo o impacto sobre o aumento da resistência bacteriana $^{5}$.

Em estudo realizado na cidade de São Paulo constatou-se que $68 \%$ das prescrições de antibióticos para tratamento de infecções respiratórias em crianças menores de sete anos eram inade- quadas, tendo sido prescritos para tratamento de resfriado comum, doença de etiologia viral ${ }^{5}$.

Outro problema que pode ocorrer pelo uso abusivo de antibióticos é o mascaramento de certos sintomas que poderá ter como consequência uma maior dificuldade para realizar o diagnóstico correto de doenças graves, aumentando, portanto, o tempo de exposição do paciente ao agente infeccioso, o que pode resultar em agravamento do processo infeccioso ${ }^{6}$. O desenvolvimento de reações adversas devido ao uso dos antibióticos deve ser também considerado para traçar um panorama mais completo dessa problemática. O uso de antibióticos é responsável por grande incidência de reações adversas, desde diarreia por tetraciclina até arritmia relacionada ao uso de fluoroquinolonas e macrolídeos, bem como mielossupressão por trimetoprina ${ }^{3}$. Interação com outras classes de medicamentos também se junta aos problemas anteriormente citados. Como exemplo, pode-se citar a perda de atividade de contraceptivos orais quando da utilização concomitante com alguns antibióticos, podendo resultar em gravidez indesejada ${ }^{7}$.

Um estudo descreve um projeto de educação da população quanto à utilização correta e consciente de drogas antimicrobianas, visando alterar hábitos de consumo e automedicação; e também a reeducação dos profissionais de saúde em relação aos hábitos de prescrição e indicação de antimicrobianos ${ }^{4}$. Este estudo vem de encontro às recomendações da OMS, em seu plano de combate ao uso irracional de medicamentos, no qual recomenda fomentar a educação da população a respeito do seu uso. Para tanto é necessário conhecer as características de consumo de medicamentos pela população $0^{2,8}$.

O presente trabalho objetivou conhecer o perfil de utilização, prescrição e comercialização de antimicrobianos pelos diferentes estratos demográficos e sociais da população de Jataí (GO), a fim de que medidas educativas e de controle possam, futuramente, ser implementadas de forma eficiente e dirigida.

\section{Metodologia}

Trata-se de um estudo transversal de base populacional no município de Jataí, GO, onde foi realizado um sorteio de 13 entre os 88 setores censitários utilizados pelo Instituto Brasileiro de Geografia e Estatística (IBGE) no recenseamento da cidade. Em seguida, para cada setor escolhido, foram sorteados um quarteirão, uma esquina e a 
primeira casa a ser realizada a entrevista. A partir da primeira residência, foi selecionada, em sentido horário, uma a cada três, até que todos os domicílios escolhidos randomicamente fossem visitados.

De acordo com estudos estatísticos preliminares, levando-se em conta uma população estimada em 2008 em 85.491 habitantes, a amostra estudada deveria conter, no mínimo, 470 indivíduos, admitindo-se uma prevalência esperada de $8 \%$, de acordo com o trabalho realizado por Berquó et al. ${ }^{4}$ na cidade de Pelotas, RS. Além disso, o cálculo foi realizado levando-se em consideração uma margem de erro de três pontos percentuais e um fator de correção de 1,5 decorrente do delineamento do estudo (amostra por conglomerado).

$\mathrm{O}$ instrumento de pesquisa conteve questões relativas ao uso de antimicrobianos por todos os moradores da residência selecionada. Os indivíduos entrevistados deveriam ser capazes de fornecer dados acerca do consumo de antimicrobianos pelos outros moradores da residência.

Os questionários aplicados eram estruturados com questões referentes às variáveis socioeconômicas tais como, renda familiar mensal; idade; sexo; escolaridade; estado civil e número de pessoas residentes no domicílio. Além de questões a respeito da utilização do antibiótico, tais como: se houve utilização por algum morador da residência no último mês; o nome do medicamento; quem indicou sua utilização (médico, farmacêutico ou outro); se o tratamento foi finalizado, se os horários foram respeitados, se o tratamento surtiu o efeito esperado, se houveram efeitos colaterais, se a pessoa indica antimicrobianos para familiares e amigos e o conhecimento a respeito do uso deste tipo de medicamento sem prescrição médica. A prevalência do uso de antimicrobiano nos últimos 30 dias foi verificada através das respostas positivas do participante. Foram tabulados os dados obtidos e determinadas as frequências relativas de uso de antimicrobianos de acordo com as questões que compunham o questionário.

Para a análise dos dados empregou-se os testes não paramétricos de Qui-quadrado, que verificou a associação do sexo com o uso de antibióticos e o teste de Fisher para a variável renda familiar. Para tal, foi utilizado o software XLSTAT 2011.

\section{Resultados}

Foram visitados 192 domicílios, e os resultados apresentados referem-se aos hábitos de consumo de antimicrobianos de um total de 655 indivíduos. Dentre estes, 44 referiram o uso de antimicrobianos nos 30 dias anteriores a entrevista, o que representa uma prevalência de $6,8 \%$ (Tabela 1).

A prevalência de utilização de antimicrobianos foi maior entre as mulheres $(65,9 \%)$ enquanto os homens representaram $34,1 \%$, porém não houve associação entre o sexo e o uso de antimicrobianos $(\mathrm{p}=0,955)$. Pode-se constatar um aumento da utilização de antimicrobianos à medida que aumentou a faixa etária dos indivíduos que fizeram uso de antibióticos, sendo que os indivíduos de 20 a 59 anos representaram 50\% daqueles que utilizaram este tipo de medicamento nos últimos 30 dias. No entanto, este dado não foi analisado estatisticamente, pois foi obtida somente a idade do indivíduo que fez uso de antibióticos naquela residência participante da entrevista, e não de todos os moradores do local. Quanto à renda familiar, foi verificada maior prevalência de utilização no estrato 1 a 3 salários mínimos $(59,1 \%)$, mas também não houve dependência deste fator com o uso de antibióticos $(\mathrm{p}=1,000)$.

Tabela 1. Prevalência de utilização de antimicrobianos nos últimos 30 dias de acordo com as variáveis individuais e socioeconômicas.

\begin{tabular}{lc}
\hline \multicolumn{1}{c}{ Variável } & $\mathbf{N}(\%)$ \\
\hline $\begin{array}{l}\text { Uso de Antimicrobiano } \\
\text { Sexo }\end{array}$ & $44(6,8 \%)$ \\
$\quad$ Feminino & $29(65,9 \%)$ \\
Masculino & $15(34,1 \%)$ \\
Faixa etária & \\
0 a 4 anos & $5(11,4 \%)$ \\
5 a 9 anos & $4(9,1 \%)$ \\
10 a 19 anos & $5(11,4 \%)$ \\
20 a 59 anos & $22(50 \%)$ \\
$>60$ anos & $8(18,2 \%)$ \\
Renda familiar & $9(20,4 \%)$ \\
até 1 salário mínimo & $26(59,1 \%)$ \\
1 a 3 salários & $6(13,6 \%)$ \\
3 a 5 salários & $1(2,3 \%)$ \\
5 a 7 salários & $01(2,3 \%)$ \\
7 a 9 salários> 9 salários & $1(2,3 \%)$ \\
Não informou &
\end{tabular}


A maioria das pessoas entrevistadas informou que a indicação do antimicrobiano foi feita por médico ou dentista $(81,8 \%)$, apenas $9,1 \%$ referiram a automedicação e $9,1 \%$ mencionaram que utilizaram o medicamento por indicação de um farmacêutico. Ressalta-se, portanto, que a metodologia da pesquisa não incluía a verificação da receita médica. Os antimicrobianos mais utilizados foram amoxicilina $(40,1 \%)$, e cefalexina $(13,6 \%)$. Doze pessoas $(27,3 \%)$ relataram não saber o nome do medicamento utilizado, dentre estas, $92 \%$ relatam que a prescrição do antimicrobiano foi feita por médico/dentista. Dentre os motivos de utilização mais citados pelos entrevistados, encontram-se as infecções de orofaringe $(29,5 \%)$, tratamento dentário $(13,6 \%)$, e infecção urinária/renal $(13,6 \%)$, como pode ser observado na Tabela 2.

Analisando as diferentes faixas etárias, verifica- se que as infecções de orofaringe são as principais indicações clínicas para o uso de antimicrobiano até os 19 anos de idade, totalizando $20,4 \%$. Dos 20 aos 59 anos, destacam-se além das infecções de orofaringe $(9,1 \%)$, tratamento dentário (9\%), infecção urinária/renal $(11,3 \%)$ e infecções de pele $(4,5 \%)$. Entre a faixa etária 69 anos ou mais, destaca-se cirurgias.
A pesquisa revelou que $75 \%$ dos entrevistados utilizaram o medicamento durante o período indicado pelo profissional, finalizando assim o tratamento. Entretanto, 2,3\% dos entrevistados relataram uso do antimicrobiano por um tempo superior ao indicado pelo profissional. Constatou-se ainda que 4,6\% dos entrevistados não finalizaram o tratamento, relatando como motivo do abandono a melhora dos sintomas $(2,3 \%)$, outros $(2,3 \%)$ abandonaram o tratamento em virtude dos efeitos colaterais.

No que tange os horários de uso do medicamento, 86,3\% dos entrevistados relataram cumpri-los rigorosamente durante o tratamento. Por outro lado, 4,6\% dos entrevistados mencionaram não cumprir os horários estabelecidos, alegando, para tanto, o esquecimento como motivo.

A maioria dos entrevistados (86,3\%) afirmou constatar o desaparecimento dos sintomas de infecção após o tratamento com antimicrobianos, $2,3 \%$ encontravam-se ainda em tratamento e 6,8\% relataram que não obtiveram melhora.

Ao serem questionados sobre os efeitos colaterais causados pelo uso de antimicrobianos, $79,5 \%$ dos entrevistados relataram não verificar efeitos colaterais e $20,5 \%$ descreveram sono, fadiga, vesículas corporais, enjôo, irritação, alergia

Tabela 2. Prevalência do uso de antimicrobianos nos últimos 30 dias de acordo com a indicação clinica e faixa etária.

\begin{tabular}{|c|c|c|c|c|c|c|}
\hline \multirow[b]{2}{*}{ Indicação Clínica } & \multicolumn{5}{|c|}{ Faixa etária (em anos) } & \multirow[b]{2}{*}{ Total } \\
\hline & $0-4$ & $5-9$ & $10-19$ & $20-59$ & $>60$ & \\
\hline Infecção Orofaringe & 6,8 & 6,8 & 6,8 & 9,1 & - & 29,5 \\
\hline Infecção urinária/renal & - & - & - & 11,3 & 2,3 & 13,6 \\
\hline Tratamento dentário & - & 2,3 & 2,3 & 9,0 & - & 13,6 \\
\hline Otites & 2,3 & - & - & 2,3 & - & 4,6 \\
\hline Cirurgia & - & - & - & 2,3 & 4,3 & 6,6 \\
\hline Infecção de pele & - & - & - & 4,5 & - & 4,5 \\
\hline Gripe & 2,3 & - & - & - & - & 2,3 \\
\hline Gastrite & - & - & - & 2,3 & - & 2,3 \\
\hline Úlcera gástrica & - & - & - & 2,3 & - & 2,3 \\
\hline Espinha interna & - & - & - & 2,3 & - & 2,3 \\
\hline Infecção intestinal & - & - & - & - & 2,3 & 2,3 \\
\hline Infecção cavidade oral & - & - & - & - & 2,3 & 2,3 \\
\hline Infecção ungueal & - & - & 2,3 & - & - & 2,3 \\
\hline Mordida de cão & - & - & - & - & 2,3 & 2,3 \\
\hline Febre & - & - & - & - & 2,3 & 2,3 \\
\hline Micose & - & - & - & 2,3 & - & 2,3 \\
\hline Queimadura & - & - & - & - & 2,3 & 2,3 \\
\hline Alergia & - & - & - & 2,3 & - & 2,3 \\
\hline Total & 11,4 & 9,1 & 11,4 & 50 & 18,1 & 100 \\
\hline
\end{tabular}


e cólicas como efeitos colaterais causados pelo uso desse tipo de medicamento.

A maioria dos entrevistados (79,5\%) relatou não indicar antibióticos para familiares e amigos e $20,5 \%$ mencionaram esta prática. Um número considerável dos entrevistados (25\%) relatou desconhecer as consequências do uso de antimicrobianos sem prescrição médica, e 75\% relataram conhecer os riscos da automedicação. No entanto, $14 \%$ não souberam responder o porquê de não ser recomendado o uso de antibiótico sem prescrição médica. Dentre os que responderam (61\%), apenas $4,6 \%$ estavam corretos em sua resposta. As respostas erradas ou incompletas mais comuns em relação ao questionamento "Você sabe por que não é recomendável o uso de antimicrobianos sem prescrição médica?” foram "surgimento de efeitos colaterais" (16,1\%), "causam mal à saúde" $(9,1 \%)$, "cada caso é um caso" $(9,1 \%)$ e "não sabe o que a pessoa tem" (4,6\%).

\section{Discussão}

O presente estudo apresenta como limitação, basear-se em dados relatados pelos entrevistados, que podem apresentar algum grau de incerteza. Foi verificado uma prevalência global de utilização de antimicrobianos de 6,8\%, apresentando consonância com o estudo de Berquó et al. ${ }^{4}$, que encontrou prevalência de utilização de antimicrobianos nos últimos 30 dias de $8 \%$.

Os dados em relação à indicação do antimicrobiano apresentam-se aparentemente favoráveis, $81,8 \%$ dos entrevistados revelou que a indicação do medicamento foi feita por médico/dentista. No entanto, dentre estes, $25 \%$ revelaram não saber o nome do antimicrobiano, o que se pode inferir certo grau de incerteza no relato do entrevistado. Vale ressaltar que a presente pesquisa foi realizada antes da RDC ${ }^{\circ} 44$ de outubro de $2010^{9}$, que regulamenta a venda de antimicrobianos somente com receita médica.

Verifica-se dentre as indicações, mesmo em casos isolados, eventos em que não deveriam ser utilizados antimicrobianos, como gripe, que é uma infecção viral, febre e alergia. Fatos estes que podem contribuir para a resistência microbiana, configurando um grave problema de saúde, uma vez que as alternativas terapêuticas ficam restritas, comprometendo a saúde do indivíduo doente, além de representar também uma ameaça à população em geral. Adicionalmente, uma vez estabelecida a infecção por microrganismo resistente, em geral, as opções terapêuticas são mais caras, elevando consideravelmente o custo do tratamento e prolongando o período de internação.

Verificou-se ainda, que um número considerável dos entrevistados indica o uso de antimicrobianos para outras pessoas. Outro fato que chamou a atenção foi o desconhecimento da população estudada acerca dos riscos do uso indiscriminado de antimicrobianos. Apenas uma pessoa respondeu satisfatoriamente a pergunta a respeito dos riscos do consumo abusivo de antimicrobianos.

Os resultados revelam que o desconhecimento da população da cidade de Jataí (GO) acerca dos riscos da utilização abusiva de antimicrobianos está relacionado à falta de orientação. Apesar de relatar consumo de antimicrobiano sob orientação médica, a população estudada desconhece os perigos de sua utilização. Verificou-se com este estudo, a necessidade de ações que orientem a população sobre os riscos relacionados ao uso de antimicrobianos.

\section{Colaboradores}

A Braoios trabalhou na elaboração e revisão do manuscrito, e na análise dos dados; ACS Pereira na elaboração do manuscrito, coleta, tabulação e análise dos dados; e, AA Bizerra, OF Policarpo, NC Soares e AS Barbosa na coleta dos dados. 


\section{Referências}

1. Wannmacher L. Uso indiscriminado de antibióticos e resistência microbiana: uma guerra perdida? Uso Racional de Medicamentos 2004; 1(4):1-6.

2. Organización Mundial de la Salud (OMS). Uso racional de los medicamentos: progresos realizados en la aplicación de la estrategia farmacéutica de la OMS, Informe de la Secretaria, 118a reunión del consejo ejecutivo. Ginebra: OMS; 2006.

3. Nicolini P, Nascimento JWL, Greco KV, Menezes FG. Fatores relacionados à prescrição médica de antibióticos em farmácia pública da região oeste da cidade de São Paulo. Cien Saude Colet 2008, 13(Supl.):689-696.

4. Berquó LS, Barros AJD, Lima RC, Bertoldi AD. Utilização de antimicrobianos em uma população urbana. Rev Saude Publica 2004; 38(2):239-246.

5. Bricks LF. Uso judicioso de medicamentos em crianças. J Pediatr 2003; 79(Supl. 1):S107-S114.

6. Kunin CM, Liu YC. Excessive use of antibiotics in the community associated with delayed admission and masked diagnosis of infectious diseases. $J \mathrm{Mi}$ crobiol Immunol Infect 2002; 35(3):141-146.

7. Correa EMC, Andrade ED, Ranali J. Efeito dos antimicrobianos sobre a eficácia dos contraceptivos orais. Rev Odontol Univ São Paulo 1998; 12(3):237240.

8. Leite SN, Vieira M, Veber AP. Estudo de utilização de medicamentos: uma síntese de artigos publicados no Brasil e América Latina. Cien Saude Colet 2008; 13(Supl.):793-802.

9. Brasil. Agência Nacional de Vigilância Sanitária (Anvisa). RDC n ${ }^{\circ} 44$, de 26 de outubro de 2010. Dispõe sobre o controle de medicamentos à base de substâncias classificadas como antimicrobianos, de uso sob prescrição médica, isoladas ou em associação e dá outras providências. Diário Oficial da União 2010; 27 out.

Artigo apresentado em 15/01/2012

Aprovado em 20/02/2012

Versão final apresentada em 11/03/2012 